\title{
DESAFÍOS ACTUALES PARA LA REDUCCIÓN DEL RIESGO DE DESASTRES: NUEVOS ESCENARIOS Y CAMBIOS DE PARADIGMAS
}

Nelly Gray de Cerdán ${ }^{1 *}$

\section{RESUMEN}

Este prólogo para el segundo año de la revista REDER nos advierte del rumbo que nuestras sociedades están siguiendo actualmente, y de las consecuencias que en algunos lugares ya se observan como resultado de nuestros modelos de desarrollo y crecimiento. Esta advertencia es también para invitarnos a revisar los paradigmas vigentes, y para integrar la reducción del riesgo de desastres a los diferentes esquemas de desarrollo.

\section{PALABRAS CLAVE}

Reducción de riesgos, desastres, Marco de Sendai

\section{CURRENT CHALLENGES FOR DISASTER RISK REDUCTION: NEW SCENARIOS AND PARADIGM CHANGES}

\section{ABSTRACT}

This introduction for the second year of the REDER journal subtly warns us of the course that our societies are currently underway, as well as the consequences of such trajectory and our development and growth models. This warning is also an invitation to review the prevailing paradigms, and to consider disaster risk reduction as a fundamental element of future development schemes.

\section{KEYWORDS}

Risk reduction, Disasters, Sendai Framework

1. Centro de Estrategias Territoriales para el Mercosur (CETEM), Facultad de Filosofía y Letras, Universidad Nacional de Cuyo, Argentina.

*Autor de correspondencia: nellyamaliag@gmail.com

\section{Formato cita}

Recomendada (APA): Gray de Cerdán, N. (2018). Desafíos actuales para la Reducción del Riesgo de Desastres. Nuevos escenarios y cambios de paradigmas. REDER, 2(1), pp.1-3

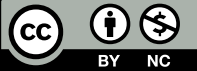

Todos los artículos publicados en REDER siguen una política de Acceso Abierto y se respaldan en una Licencia CreativeCommons Atribución-NoComercial 4.0 Internacional.

Revista de Estudios Latinoamericanos sobre Reducción del Riesgo de Desastres (REDER)

Diseño: Lupe Bezzina Tipografías: Hospital 


\section{PRÓLOGO}

El futuro marca un desafío a la imaginación y la creatividad humana en forma permanente: hoy alcanzar un desarrollo ambientalmente sostenible, más seguro, territorialmente más cohesionado y resiliente exige afrontar cambios de conductas y modos de intervención frente a una naturaleza crecientemente hostil, frente a retos sociales, económicos, energéticos, tecnológicos y ambientales inéditos.

En estos años y los próximos, la percepción de los efectos del cambio climático, el aumento de los desastres y su incidencia sobre los modelos territoriales, serán retos sobre los que se deben anticipar soluciones para evitar consecuencias irreparables, altos costos ambientales y económico-sociales, que seguramente van a aparecer o aumentar por la debilidad y el desorden en la gestión, la ineficiencia de las políticas públicas, el aumento de la pobreza y el deterioro social.

Los problemas están planteados y ya se observan los primeros impactos: nuevas regulaciones y funcionamiento económico de la sociedad mundial, escasez y costos crecientes de la energía y los alimentos, crisis en el sector financiero mundial, en los mercados, en la construcción, en el crecimiento de las ciudades, guerras, terrorismo, desplazamientos y migraciones humanas, nuevos costos del transporte y desarticulación progresiva y sistemática del capitalismo dominante, amenazan con cambiar rotundamente el mapa geográfico del mundo: grandes potencias se debilitan y otras surgen con fuerza, pero todas acumulando vulnerabilidades y riesgos no calculados en el proceso.

Resulta indispensable - en consecuencia - revisar los paradigmas vigentes, incentivar un mayor compromiso por parte de la sociedad civil, fortalecer la gobernanza y proyectar el futuro con una visión integradora e inclusiva: reconocer, caracterizar y comprender el riesgo, permitirá encontrar soluciones realistas y sustentables.

El compromiso y la responsabilidad de los gestores públicos y privados, de los inversores, empresarios y productores, así como la participación social organizada deben ser -en función de las capacidades nacionales- promotores de la integración de enfoques de gestión y reducción del riesgo de desastres en las políticas y programas locales, regionales y nacionales, para asegurar la sostenibilidad de los logros en materia de desarrollo. Se deben también actualizar y/o generar leyes innovadoras, capaces de proteger a las personas, las comunidades y los países, a sus medios de subsistencia, su salud, su patrimonio cultural, sus activos socioeconómicos y sus ecosistemas, reforzando la resiliencia individual y social y aportando los presupuestos y fondos necesarios para financiar el esfuerzo.

Los artículos que integran este segundo número de REDER, han captado con fuerza el mensaje de Sendai: avanzan en clarificar, ampliar y revisar las premisas existentes, tomando como base las herramientas de hoy, pero con una mirada innovadora y creativa. Los análisis y pensamientos que expresan van desde ricos análisis científicos holísticos y universales sobre la agenda derivada de esa reunión, hasta la posibilidad de redescubrir, describir y valorizar los elementos más sencillos de la vulnerabilidad cotidiana y local, en la certeza que la creatividad humana será puesta a prueba en un amplio contexto territorial donde todo cuenta.

Algunos resultados del trabajo desarrollado en el contexto de Sendai por la comunidad internacional fueron presentados durante la última reunión de la Plataforma Global 2017 de RRD en Cancún, México, donde se potenció y sostuvo que el Marco de Sendai es innovador por su enfoque centrado en el ser humano. Se subrayó además la necesidad de comprender que las acciones humanas influyen en el medio ambiente y se aconsejó en todos los campos, dar prioridad a las medidas de prevención para abordar problemas mundiales como el cambio climático, el riesgo de desastres y la pobreza.

Con fuerza y en varias oportunidades, se señaló que la mejor manera de implementar estas medidas es mediante la coordinación de las políticas de RRD con los Objetivos de Desarrollo Sostenible (ODS), exhortando a todas las partes interesadas a intensificar sus esfuerzos para reducir los niveles existentes de vulnerabilidad y exposición, prestando especial atención a la pobreza, la inequidad, el aumento de los asentamientos informales, el deterioro del medio ambiente en el contexto del cambio climático. 
Lo cier to es que los retos territoriales frente a los cambios que ya se están produciendo y los que se avecinan, son múltiples, complejos y predomina la incertidumbre. La situación desafía a la creatividad científica y social de una Humanidad que deberá renovar y/o crear nuevos conceptos, metodologías y procedimientos, a la par que imaginar las vías operativas de adaptación necesarias para convivir con ellos y superar los desafíos. Hoy más que nunca están vigentes las palabras de Charles Darwin: "No es la especie más fuerte la que sobrevive, ni la más inteligente, sino la que responde mejor al cambio". 